\title{
Índice de área foliar em canola cultivada sob variações de espaçamento e de densidade de semeadura
}

\author{
Leaf area index of canola under varying row spacing and plant density of sowing
}

\author{
Geraldo Chavarria $^{I^{*}}$ Gilberto Omar Tomm ${ }^{\mathrm{II}}$ Alexandre Muller ${ }^{\mathrm{I}}$ Heloisa Ferro Mendonça ${ }^{\mathrm{I}}$ \\ Naiana Mello ${ }^{\mathrm{I}}$ Maico Serafini Betto ${ }^{\mathrm{I}}$
}

\section{RESUMO}

\begin{abstract}
O objetivo do presente trabalho foi estimar através de método não-destrutivo o índice de área foliar do híbrido de canola Hyola 61 em variações de espaçamento e densidade de semeadura. $O$ delineamento experimental foi de blocos casualizados com parcelas subdivididas, sendo que nas parcelas foram distribuídos os espaçamentos entre linhas (17, $34,51$ e $68 \mathrm{~cm})$ e nas subparcelas as densidades $(15,30,45 e$ 60 plantas $\left.\mathrm{m}^{-2}\right)$. Para determinação do comprimento, largura do limbo foliar e da área foliar, bem como estabelecimento de uma correlação entre essas variáveis foram coletadas aleatoriamente 250 folhas. Posteriormente, foram selecionadas aleatoriamente quatro plantas por unidade experimental, que tiveram todas as folhas medidas quanto ao comprimento $e$ largura para estimativa da área foliar e do índice de área foliar. O comprimento do limbo foliar é a variável biométrica com maior correlação com a área foliar. Um comportamento linear entre o adensamento de plantas e o índice de área foliar nos espaçamentos de 34, 51 e $68 \mathrm{~cm}$ no híbrido Hyola 61 foi observado. $O$ índice de área foliar das plantas foi menor no espaçamento de $17 \mathrm{~cm}$, com a densidade de 60 plantas $\mathrm{m}^{-2}$. Para a manutenção do índice de área foliar do híbrido Hyola 61, é recomendável usar o espaçamento de $17 \mathrm{~cm}$ com a densidade 45 plantas $\mathrm{m}^{-2}$.
\end{abstract}

Palavras-chave: fotossíntese, crescimento, variáveis de produtividade, manejo.

\section{ABSTRACT}

The aim of this work was to estimate leaf area index of the canola cultivar 'Hyola 61' under variations of row spacing and density of sowing by a non-destructive method. The experimental design consisted of a split plot with four blocks with row widths of $17,34,51$ and $68 \mathrm{~cm}$ and plant populations of $15,30,45$ and $60 \mathrm{~m}^{2}$. Two hundred and fifth leaves were collected at random and mesure width $(C)$, length $(L)$ and leaf area $(L A)$ and the parameters were correlated. Also the leaves of four plants of each plot, selected at random, were measured $L$ and $C$ and estimated the leaf area index (LAI). Width leaf was the biometric parameter that shows highest correlation with LA. There is a linear relation between plant density and leaf area index in spacing of 34,51 and $68 \mathrm{~cm}$ in 'Hyola 61'. The row width of $17 \mathrm{~cm}$ and plant population of 60 plants per square meter to reduces the LAI. However, aiming LAI maintenance in Hyola 61 is recommended uses of row width of $17 \mathrm{~cm}$ and plant population of 45 plants per square meter.

Key words: photosynthesis, growth, yields parameters, management.

\section{INTRODUÇÃO}

A canola (Brassica napus L.) foi desenvolvida através do melhoramento genético da colza, uma espécie oleaginosa, pertencente à família Brassicaceae (crucíferas), a partir da qual foram selecionadas cultivares com reduzidos teores de glucosinolatos e ácido erúcico, nocivos ao organismo animal (FIGUEIREDO et al., 2003).

Essa cultura tem uma grande importância econômica, destacando-se como a terceira oleaginosa mais produzida mundialmente em decorrência da qualidade e conteúdo de óleo dos grãos (34 a 38\%) e elevada quantidade de proteína (24 a 27\%) (TOMM, 2007).

'Universidade de Passo Fundo (UPF), CP 611, 99001-970, Passo Fundo, RS, Brasil. E-mail: geraldochavarria@upf.br. *Autor para correspondência.

IIEmbrapa Trigo, Centro Nacional de Pesquisa em Trigo, Passo Fundo, RS, Brasil. 
O óleo de canola é de elevado teor de ômega-3 (ácido linolênico), vitamina $\mathrm{E}$, gorduras monoinsaturadas, baixo teor de gorduras saturadas e melhor composição de ácidos graxos, comparativamente com outros óleos vegetais (IRIARTE \& VALETTI, 2008), de forma que é uma importante fonte de "gorduras benéficas" para a alimentação humana, sendo utilizado há dezenas de anos nos países europeus (PIAZZA \& FOGLIA, 2001).

Outra relevância da cultura, do ponto de vista da utilização de seu óleo, é a necessidade da produção crescente de bioenergia e biocombustíveis, o que vem alavancando o cultivo da canola no Brasil (BARBOSA et al., 2008), já que possui especificações que favorecem a produção de biodiesel. Além disso, seu resíduo (farelo) é utilizado para a fabricação de rações usadas na alimentação animal.

$\mathrm{Na}$ cultura da canola, os esforços em pesquisa e desenvolvimento são incipientes e a maioria dos produtores brasileiros está apenas iniciando o seu cultivo, de forma que há carência de informações técnico-científicas referentes ao seu manejo, como, por exemplo, níveis adequados de espaçamento e densidade de semeadura. Entretanto, o aumento na demanda brasileira pela canola fez crescer o incentivo à pesquisa dessa cultura, tanto na iniciativa privada como em instituições públicas (CONAB, 2010).

Dentre às práticas empregadas para o incremento da produtividade, $\mathrm{o}$ arranjo espacial com menor espaçamento entre as linhas de semeadura aumenta a equidistância entre as plantas, constituindo uma alternativa importante para melhoria de resultados (VON PINHO et al., 2008). Todavia, existe um limite máximo de plantas em um determinado espaço, em função da competição fisiológica entre elas.

Como a produtividade está vinculada diretamente à intensidade e a duração do período de atividade fotossintética (assimilação líquida de carbono) das plantas, o conhecimento da área foliar é instrumental à adequação da distribuição espacial de uma população de plantas, sendo uma informação fundamental para aproximar o rendimento das lavouras do potencial genético de produtividade de uma cultura. Dessa forma, o índice de área foliar $\left(\mathrm{m}^{2}\right.$ de área das folhas por $\mathrm{m}^{2}$ de área de solo) das plantas cultivadas é uma informação chave para obtenção de níveis ótimos de área foliar fotossintetizante e elevação da produtividade (WATSON, 1952).

A estimativa da área foliar pode ser efetuada empregando métodos destrutivos e não-destrutivos, dos quais, dentro dos não-destrutivos, fundamentais do ponto de vista de manutenção da folha nas plantas para o acompanhamento do ciclo da cultura, destacamse a utilização de dimensões foliares, imagens digitais e o uso de discos foliares (BIANCO et al., 2005).
Assim, o objetivo deste trabalho foi estimar, através de método não-destrutivo, o índice de área foliar do híbrido de canola Hyola 61 e compará-lo sob variações de espaçamento entre linhas e densidade de semeadura.

\section{MATERIAL E MÉTODOS}

O experimento foi realizado na estação experimental da Universidade de Passo Fundo (28 ${ }^{\circ} 14^{\prime}$ 'S, $52^{\circ} 22^{\prime}$ O), em Passo Fundo-RS, no ano agrícola de 2010, empregando-se uma semeadora de parcelas experimentais Sêmina com as linhas ajustadas aos diversos espaçamentos para semear o híbrido de canola de ciclo médio, Hyola 61 ( $\mathrm{PG}=90 \%, \mathrm{MMS}=4,8 \mathrm{~g})$. A semeadura foi realizada em 03/06/2010, simultaneamente à adubação de semeadura, com a aplicação de $300 \mathrm{~kg} \mathrm{ha}^{-1}$ de NPK da fórmula 05-25-25, cuja emergência ocorreu em 13/06/2010 e o corteenleiramento, para posterior colheita, foi realizado em 11/11/2010. A adubação de cobertura constou de $100 \mathrm{~kg}$ de $\mathrm{N} \mathrm{ha}^{-1}$, aplicado na forma de ureia em 27/07/2010.

O delineamento experimental utilizado foi de blocos ao acaso em parcelas subdivididas e quatro repetições, sendo que os tratamentos das parcelas constaram de quatro espaçamentos entre linhas (17, 34,51 e $68 \mathrm{~cm}$ ) e das subparcelas de quatro densidades de plantas $\left(15,30,45\right.$ e 60 plantas $\left.\mathrm{m}^{-2}\right)$, totalizando 64 unidades experimentais, cada uma com comprimento de cinco metros e largura variável em função do espaçamento (136, 204, 204 e $272 \mathrm{~cm}$, respectivamente, para os espaçamentos de $17,34,51,68 \mathrm{~cm})$. Ao acaso foram coletadas 250 folhas com dimensões variadas ao longo de todo o experimento, nas quais foram efetuadas medições de comprimento, largura do limbo foliar e a área foliar, empregando um integrador de área foliar (Li-3000) e estabelecendo-se uma correlação entre essas variáveis e a área foliar.

Também foram selecionadas aleatoriamente quatro plantas por unidade experimental, tendo sido medidos o comprimento, a largura do limbo foliar de todas as folhas, estimada a área foliar e, posteriormente, calculado o índice de área foliar. No período da colheita, foram avaliadas as produtividades das parcelas, colhendo-se manualmente as quatro linhas centrais de cada parcela e ajustando-se a massa de grãos para a umidade de $10 \%$.

Os resultados obtidos foram analisados através de análise de variância - ANOVA - e as médias comparadas pelo teste de Tukey a 5\% de probabilidade de erro. A partir dos valores de índice de área foliar alcançados em função da variação de espaçamento entre linhas e densidade de semeadura, foram geradas equações de regressão. 


\section{RESULTADOS E DISCUSSÃO}

Para o estabelecimento da variável mais adequada de medida do limbo foliar para estimativa da área foliar, observou-se o melhor ajuste da equação para a correlação entre comprimento do limbo foliar e a área foliar, com um coeficiente de determinação de 0,77 (Figura 1). Todavia, destaca-se que o ajuste da equação, levando em consideração a largura do limbo foliar, também teve coeficiente de determinação aceitável para a estimativa da área foliar (Figura 2).

Em trabalho realizado por MALDANER et al. (2009), foi apontado que os modelos que utilizam somente a largura ou o comprimento do limbo foliar são preferíveis, por utilizarem apenas uma das suas dimensões, havendo uma redução em $50 \%$ no número de medições de dimensão linear a serem realizadas. No caso do girassol, os mesmos autores observaram que os resultados obtidos com os modelos demonstram que deve-se optar apenas pela dimensão da largura, sendo o modelo exponencial capaz de se ajustar ao efeito da modificação de formato das folhas ao longo do ciclo de cultivo. Além disso, os autores enfatizaram que, para a cultura do girassol, a medição da largura está sujeita a um erro experimental menor do que a do comprimento, diferentemente do observado para a canola (Figura 1).

Diversos trabalhos demonstraram a eficácia do método de dimensões foliares para a estimativa da área foliar em um grande número de culturas, a exemplo do morango (PIRES et al., 1999), algodão (MONTEIRO et al., 2005), soja, braquiária (BIANCO et al., 2005), dentre outras. Essas informações da literatura corroboram os resultados encontrados para a canola (Figura 1).

Mesmo tendo ocorrido uma grande variação em tamanho e forma na folha da canola, foram observados resultados que demonstram a possibilidade de utilização das dimensões do limbo foliar como método para a estimativa da área foliar (Figura 1).

O número de folhas por planta na canola não está definido, pois, segundo a literatura, uma planta
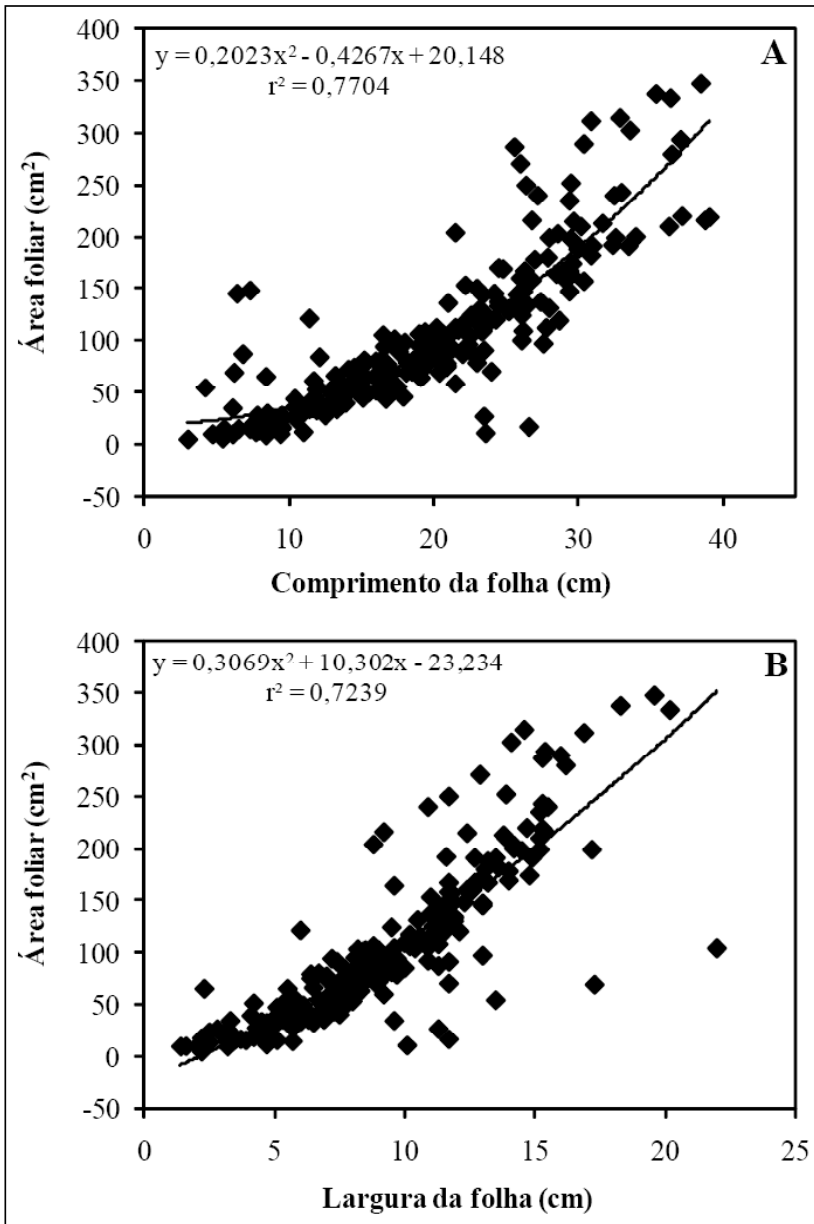

Figura 1 - Correlação da área foliar com o comprimento (A) e a largura (B) de folhas de canola. Passo Fundo, RS, 2010.

Ciência Rural, v.41, n.12, dez, 2011. 


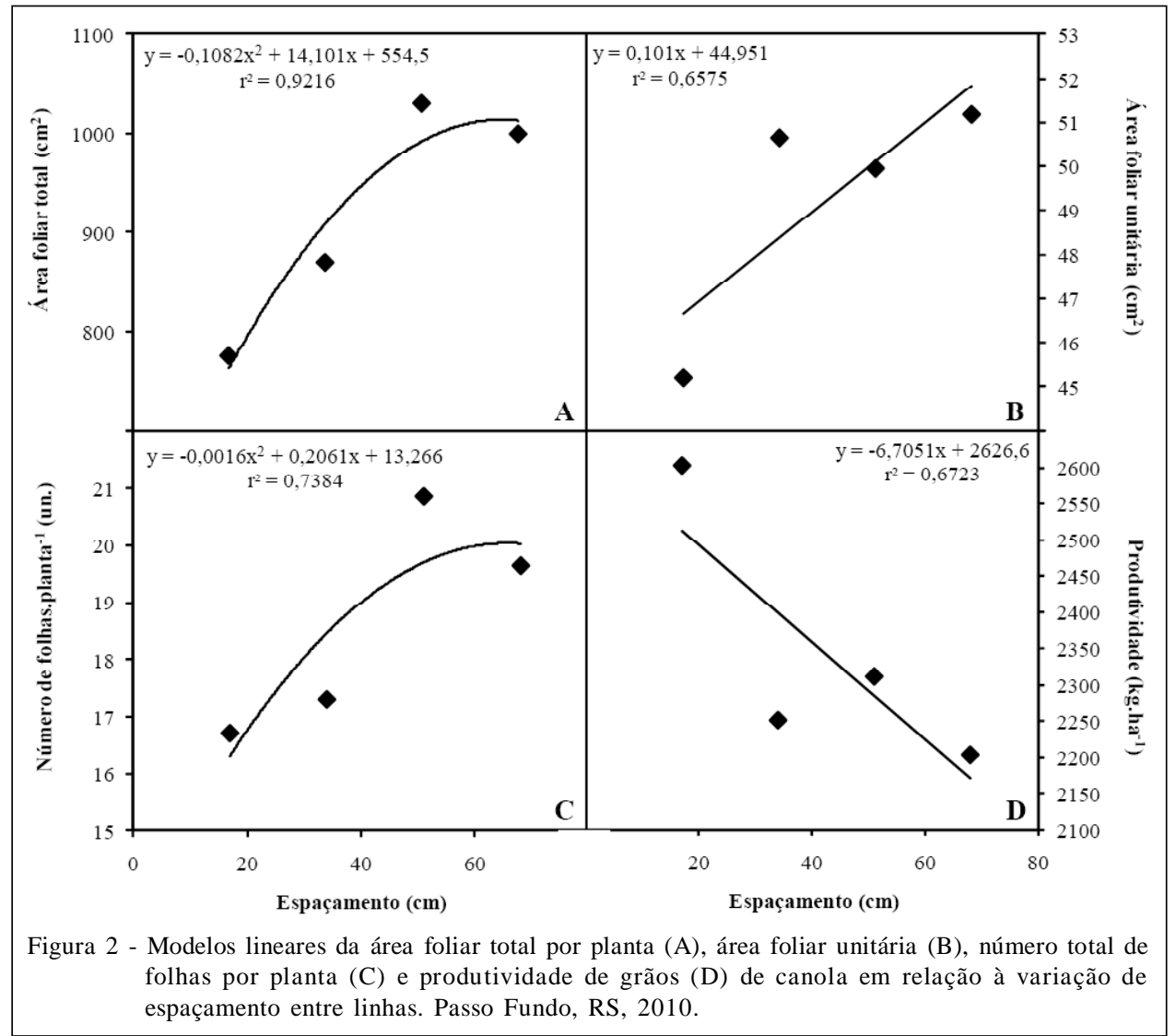

de canola pode produzir de nove a trinta folhas na haste principal, dependendo da variedade e das condições de crescimento. Entre os espaçamentos, foram observadas variações de 13 a 23 folhas por planta (Figura 2), sendo a área máxima de folhas individuais na planta, na ausência de estresse, em torno de $250 \mathrm{~cm}^{2}$ (CANOLA COUNCIL OF CANADA, 2010). Para o híbrido Hyola 61, a maior área foliar individual foi de $54,56 \mathrm{~cm}^{2}$ (Figura 2).

Considerando as variações de espaçamentos e densidades, não houve interação significativa entre estes fatores, para as variáveis área foliar total, área foliar unitária, número de folhas e produtividade. Comparando-se os espaçamentos entre as linhas, observou-se, através do ajuste proposto $\left(r^{2}=0,92\right)$, que a área foliar total começou a ser reduzida a partir do espaçamento de $51 \mathrm{~cm}(\mathrm{P}=0,030)$ (Figura 2 ), corroborando os dados do índice de área foliar presentes na figura 1. Em relação à área foliar unitária, observou-se uma tendência $\left(\mathrm{r}^{2}=0,65\right)$ ao aumento do tamanho da folha, à medida que o espaçamento foi aumentado $(\mathrm{P}=0,030)$, enquanto, para o número de folhas, houve um ajuste semelhante ao da área foliar total das plantas $\left(\mathrm{r}^{2}=0,73\right)$, podendo-se observar que, com espaçamento acima de $45 \mathrm{~cm}$, ocorre uma redução no número de folhas por planta (Figura $2 \mathrm{~A}$ e $2 \mathrm{C}$ ). Todavia, foi possível visualizar que, para as plantas cultivadas com o espaçamento de $17 \mathrm{~cm}$, ocorreu maior produção de grãos, comparativamente com os demais espaçamentos avaliados, conforme o modelo apresentado $(\mathrm{P}=0,026)$ (Figura 2D).

A importância da distribuição das folhas ao longo da lavoura para o alcance de altos rendimentos é pela melhoria na interceptação de radiação solar (ARGENTA et al., 2001), de forma que as folhas são as estruturas vegetais mais importantes para a atividade fotossintética e para nutrir o crescimento da planta. $\mathrm{O}$ índice de área foliar da canola começa a diminuir logo após o início da floração e, no florescimento pleno, os caules tornam-se a principal estrutura fotossintética, no entanto, as folhas ainda permanecem desempenhando função importante. No início do amadurecimento das síliquas, o caule é o responsável pela maior parte da fotossíntese, enquanto as folhas dão uma pequena contribuição(CANOLA COUNCIL OFCANADA, 2010). A fase de roseta é caracterizada por um aumento no índice de área foliar e, no final dessa fase, a cultura está chegando à máxima área foliar, que é alcançada na fase de botão, quando a cultura está com 30 a $60 \%$ da sua massa seca total (ALFAZL et al., 2010). 
Nos espaçamentos de 34,51 e $68 \mathrm{~cm}$, para o híbrido Hyola 61, foi observado um modelo linear de incremento do índice de área foliar, à medida que as plantas foram adensadas, com coeficientes de determinação de 0,96; 0,95 e 0,95, respectivamente. Contudo, no menor espaçamento $(17 \mathrm{~cm})$, observou-se um modelo polinomial da relação do adensamento de plantas e o índice de área foliar $\left(\mathrm{r}^{2}=0,77\right)$, indicando que, a partir de 60 plantas $\mathrm{m}^{-2}$, em espaçamento de $17 \mathrm{~cm}$, há uma redução no índice de área foliar (Figura 3A).

As plantas cultivadas com baixa densidade populacional $\left(20\right.$ plantas $\left.\mathrm{m}^{-2}\right)$ têm um índice de área foliar maior do que aquelas cultivadas em elevada densidade populacional - 126 plantas $\mathrm{m}^{-2}$ (HOSSEINI et al., 2006). Todavia, os níveis populacionais testados pelos autores foram consideravelmente altos, comparados com os testados neste trabalho. Mesmo assim, como foi citado anteriormente, houve um decréscimo no índice de área foliar quando se passou de 45 para 60 plantas $\mathrm{m}^{-2}$, pois se sabe que as plantas competem umas com as outras por água, luz e nutrientes (CANOLA COUNCIL OF CANADA, 2010). Pelo exposto, a adequação é crucial para equilibrar o processo fotossintético e a capacidade competitiva entre plantas.
Concordando com os dados obtidos neste trabalho, ao estudar diferentes densidades e espaçamentos em canola, MALIK et al. (2004) observaram que o índice de área foliar foi significativamente influenciado de forma distinta. Os autores observaram que, quanto menor o espaçamento, maior o índice de área foliar, sendo este índice de 2,4 e 3,09 para os espaçamentos de 10 e $20 \mathrm{~cm}$, respectivamente. Neste mesmo trabalho, observou-se que o padrão de distribuição das plantas na área não influenciou significativamente na estatura de plantas.

Plantas de B. napus geralmente desenvolvem mais folhas e maiores do que de B. rapa e têm um maior índice de área foliar, no máximo em torno de 3,0 a 6,0 e 3,5, respectivamente (CANOLA COUNCIL OF CANADA, 2010). Alguns autores consideram um índice de área foliar de 3 a 5 para a máxima produção de matéria seca na cultura da canola (BASRA et al., 2003; AHMAD et al., 2006).

O índice de área foliar de cerca de quatro é necessário para o dossel da cultura interceptar cerca de $90 \%$ da radiação solar e, neste trabalho, houve variações de 1,48 em espaçamento de $17 \mathrm{~cm}$ e 45 plantas $\mathrm{m}^{-2}$ até 5,73 em espaçamentos de $68 \mathrm{~cm}$ e densidade de

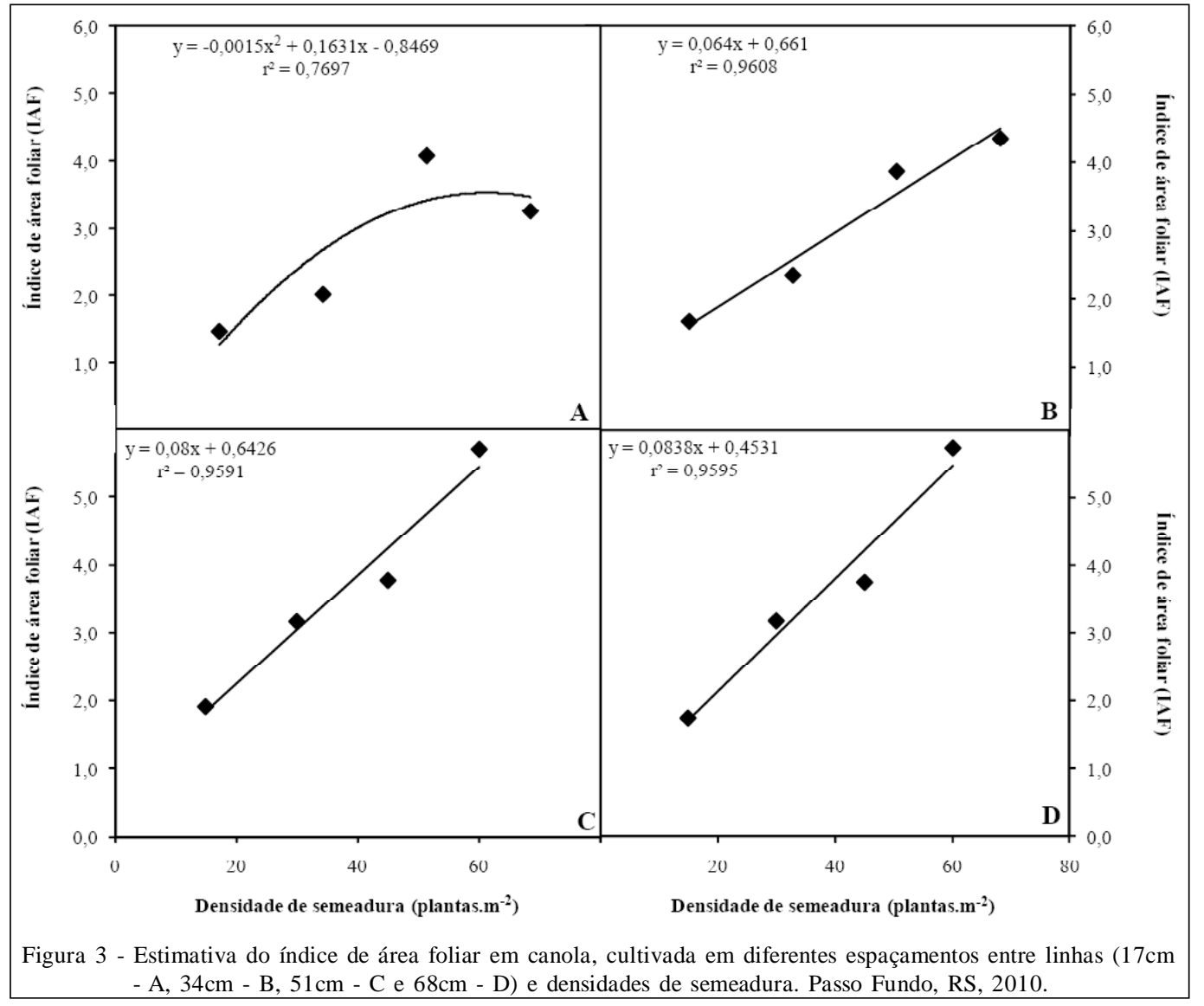

Ciência Rural, v.41, n.12, dez, 2011. 
60 plantas $\mathrm{m}^{-2}$ (Figura 2), porém, essas informações devem ser interpoladas com os resultados de produção, pois entende-se que, quanto maior a área foliar exposta ao sol, mais matéria seca da cultura pode ser produzida por dia e maior será a taxa de crescimento da cultura (CANOLA COUNCIL OF CANADA, 2010). Contudo, em algumas situações, poderá haver maior índice de área foliar com o elevado sombreamento de folhas, o que afetará a produtividade.

De acordo com os resultados do índice de área foliar e produtividade, pode-se sugerir que a opção mais recomendada ao produtor é a utilização de espaçamento de $17 \mathrm{~cm}$ com densidade de até 45 plantas $\mathrm{m}^{-2}$ por hectare (Figura 2 e 3 ). Para as condições brasileiras, destacou-se a importância de um espaçamento de até $45 \mathrm{~cm}$ e um número mínimo de 40 plantas $\mathrm{m}^{-2}$ para assegurar um maior potencial de rendimento (TOMM, 2007).

\section{CONCLUSÃO}

O comprimento do limbo foliar do híbrido Hyola 61 é a variável biométrica com maior correlação com a estimativa da área foliar. A relação entre o adensamento de plantas e o índice de área foliar nos espaçamentos de 34,51 e $68 \mathrm{~cm}$ no híbrido Hyola 61 tem comportamento linear, sendo que, para a manutenção do índice de área foliar do híbrido Hyola 61 , é recomendável o uso de espaçamento de $17 \mathrm{~cm}$, combinado com a densidade 45 plantas $\mathrm{m}^{-2}$.

\section{REFERÊNCIAS}

ARGENTA, G. et al. Arranjo de plantas em milho: análise do estado-da-arte. Ciência Rural, v.31, n.6, p.1075-1084, 2001. Disponível em: 〈http://www.scielo.br/pdf/cr/v31n6/a27v31n6.pdf〉. Acesso em: 01 de jun. 2011. doi: 10.1590/S010384782001000600027.

AHMAD, G. et al. Phenology and physiology of canola as affected by nitrogen and sulfur fertilization. Journal of Agronomy, v.5, n.1, p.555-562, 2006. Disponível em: <http:/ /docsdrive.com/pdfs/ansinet/ja/2006/555-562.pdf>. Acesso em: 21 jan. 2011. doi: 10.3923/ja.2006.555.562.

ALFAZL, F.A. Determination of phenological response of spring canola (Brassica napus L.) genotypes to sowing date, temperature and photoperiod. Seed and Plant Production Journal, v.26, n.1, p.25-41, 2010.

BARBOSA, M.Z. et al. Agricultura de alimentos X de energia: impacto nas cotações internacionais. Análise e indicadores do agronegócio. São Paulo: Instituto de Economia Agrícola, SP, 2008. v.3, n.1. 1p.

BASRA, S.M.A. et al. Effect of storage on growth and yield of primed canola (Brassica napus) seeds. International Journal of Agriculture and Biology, v.5, n.2, p.118-120, 2003. Disponível em: <http://www.fspublishers.org/ijab/past-issues/ IJABVOL_5_NO_2/3.pdf $>$. Acesso em: 28 jan. 2011.

BIANCO, S. et al. Estimativa da área foliar de Brachiaria plantaginea usando dimensões lineares do limbo foliar. Planta
Daninha, v.23, n.4, p.597-601, 2005. Disponível em: <http:/ $/ \mathrm{www}$.scielo.br/scielo.php? script $=$ sci_arttext\&pid $=$ S0 100$83582005000400006 \& \operatorname{lng}=$ pt\&nrm=iso $>$. Acesso em: 28 jan. 2011. doi: 10.1590/S0100-83582005000400006.

CONAB. Acompanhamento de safra brasileira: grãos, primeiro levantamento, Outubro / 2010. Companhia Nacional de Abastecimento. Brasília: CONAB, 2010. 44p.

CANOLA COUNCIL OF CANADA. Canola. Winnipeg, 2010. 38p. Disponível em: <http://www.uscanola.com/site/files/956/ 102394/365922/501107/Canola_LCA_data.pdf>. Acesso em: 29 set. 2011.

HOSSEINI, N.M. et al. Effects of plant density and nitrogen rates on the competitive ability of canola (Brassica napus L.) against weeds. Journal of Agricultural Science and Technology, v.8, n.1, p. 281-291, 2006.

IRIARTE, L.B.; VALETTI, O.E. Cutivo da colza. Buenos Aires: Instituto Nacional de Tecnologia Agropecuária - Inta, 2008. 156p.

MONTEIRO, J.E.B.A. et al. Estimação da área foliar do algodoeiro por meio de dimensões e massa das folhas. Bragantia, v.64, n.1, p.15-24, 2005.

FIGUEIREDO, D.F. et al. Desempenho e morfometria da mucosa de duodeno de frangos de corte alimentados com farelo de canola, durante o período inicial. Revista Brasileira de Zootecnia, v.32, n.6, p.1321-1329, 2003. Disponível em: <http:// www.scielo.br/scielo.php? script $=$ sci_arttext\&pid $=$ S15 1635982003000600006>. Acesso em: 30 maio, 2011. doi: 10.1590/S1516-35982003000600006.

MALDANER et al. Modelos de determinação não-destrutiva da área foliar em girassol. Ciência Rural, v.39, n.5, p.13561361, 2009. Disponível em: <http://www.scielo.br/pdf/cr/ v39n5/a221cr1343.pdf>. Acesso em: 03 ago. 2011. doi: S010384782009000500008 .

MALIK, M.A. et al. Agro-physiological response of canola (Brassica napus L.) to different planting patterns and stand densities. Pakistan Journal of Life and Social Sciences, v.2, n.2, p.148-152, 2004. Disponível em: <http:// www.pjlss.edu.pk/pdf_files/2004_2/2004_148-152.pdf >. Acesso em: 03 ago. 2011.

PIAZZA, G.J.; FOGLIA, T.A. Rapeseed oil for oleochemical usage. European Journal of Lipid Science and Technology, v.103, n.1, p.450-454, 2001. Disponível em: <http:// on linelibrary.wiley.com/doi/10.1002/14389312(200107)103:7\%3C450::AID-EJLT450\%3E3.0.CO;2-D>. Acesso em: 26 jan. 2011. doi: 10.1002/1438-9312(200107).

PIRES, R.C.M. et al. Estimativa da área foliar do morangueiro. Horticultura Brasileira, v.17, n.2, p.86-90, 1999.

TOMM, G.O. Indicativos tecnológicos para a produção de canola no Rio Grande do Sul. Passo Fundo: Embrapa Trigo, 2007. 68p. (Embrapa Trigo. Sistema de produção, 4).

VON PINHO, R.G. et al. Adubação nitrogenada, densidade e espaçamento de híbridos de milho em sistema de plantio direto na região sudeste do Tocantins. Bragantia, v.67, n.3, p.733-739, 2008. Disponível em: <http://www.scielo.br/ scielo.php? script=sci_arttext \& pid=S $0006-$ 87052008000300023>. Acesso em: 01 fev. 2011. doi: $10.1590 / \mathrm{S} 0006-87052008000300023$.

WATSON, D.J. The physiological basis of variation in yield. Advances in Agronomy, v.4, n.1, p.101-144, 1952. 